\title{
The Predictive Value of miR-16, -29a and -134 for Early Identification of Gestational Diabetes: A Nested Analysis of the DALI Cohort
}

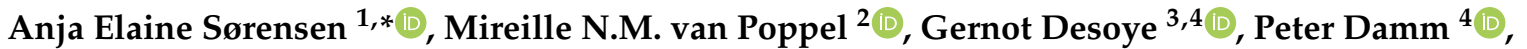 \\ David Simmons $^{5}{ }^{(\mathbb{C}}$, Dorte Møller Jensen ${ }^{6,7,8}$, Louise Torp Dalgaard ${ }^{1}$ (I) and The DALI Core Investigator Group ${ }^{\dagger}$
}

check for updates

Citation: Sørensen, A.E.; van Poppel, M.N.; Desoye, G.; Damm, P.;

Simmons, D.; Jensen, D.M.; Dalgaard,

L.T.; The Predictive Value of miR-16,

-29a and -134 for Early Identification of Gestational Diabetes: A Nested Analysis of the DALI Cohort. Cells 2021, 10, 170. https://doi.org/ 10.3390/cells10010170

Received: 15 December 2020 Accepted: 14 January 2021 Published: 15 January 2021

Publisher's Note: MDPI stays neutral with regard to jurisdictional clai$\mathrm{ms}$ in published maps and institutional affiliations.

Copyright: $\odot 2021$ by the authors. Licensee MDPI, Basel, Switzerland. This article is an open access article distributed under the terms and conditions of the Creative Commons Attribution (CC BY) license (https:// creativecommons.org/licenses/by/ $4.0 /)$.
1 Department of Science and Environment, Roskilde University, 4000 Roskilde, Denmark; 1td@ruc.dk

2 Institute of Human Movement Science, Sport and Health, University of Graz, 8010 Graz, Austria; mireille.van-poppel@uni-graz.at

3 Department of Obstetrics and Gynecology, Medizinische Universitaet Graz, 8036 Graz, Austria; gernot.desoye@medunigraz.at

4 Center for Pregnant Women with Diabetes, Department of Obstetrics, Rigshospitalet, Department of Clinical Medicine, University of Copenhagen, 2100 Copenhagen, Denmark; pdamm@dadlnet.dk

5 Macarthur Clinical School, Western Sydney University, Sydney 2560, Australia;

Da.Simmons@westernsydney.edu.au

6 Steno Diabetes Center Odense, Department of Gynecology and Obstetrics, Odense University Hospital, 5000 Odense, Denmark; Dorte.Moeller.Jensen@rsyd.dk

7 Department of Gynecology and Obstetrics, Odense University Hospital, 5000 Odense, Denmark

8 Department of Clinical Research, Faculty of Health Sciences, University of Southern Denmark, 5000 Odense, Denmark

* Correspondence: elaine@ruc.dk; Tel.: +45-4674-3994

+ The DALI Core Investigator Group are listed in Members of the DALI Core Investigator Group.

\begin{abstract}
Early identification of gestational diabetes mellitus (GDM) aims to reduce the risk of adverse maternal and perinatal outcomes. Currently, no circulating biomarker has proven clinically useful for accurate prediction of GDM. In this study, we tested if a panel of small non-coding circulating RNAs could improve early prediction of GDM. We performed a nested case-control study of participants from the European multicenter 'Vitamin D and lifestyle intervention for GDM prevention (DALI)' trial using serum samples from obese pregnant women (BMI $\geq 29 \mathrm{~kg} / \mathrm{m}^{2}$ ) entailing 82 GDM cases (early- and late- GDM), and 41 age- and BMI-matched women with normal glucose tolerance (NGT) throughout pregnancy (controls). Anthropometric, clinical and biochemical characteristics were obtained at baseline ( $<20$ weeks of gestation) and throughout gestation. Baseline serum microRNAs (miRNAs) were measured using quantitative real time PCR (qPCR). Elevated miR-16-5p, -29a-3p, and -134-5p levels were observed in women, who were NGT at baseline and later developed GDM, compared with controls who remained NGT. A combination of the three miRNAs could distinguish later GDM from NGT cases (AUC 0.717, $p=0.001$, compared with fasting plasma glucose (AUC 0.687, $p=0.004$ )) as evaluated by area under the curves (AUCs) using Receiver Operator Characteristics (ROC) analysis. Elevated levels of individual miRNAs or a combination hereof were associated with higher odds ratios of GDM. Conclusively, circulating miRNAs early in pregnancy could serve as valuable predictive biomarkers of GDM.
\end{abstract}

Keywords: gestational diabetes mellitus; microRNAs; predictive biomarker; serum; circulating microRNA; miR-16-5p; miR-29a-3p; miR-134-5p; miR-122-5p; randomized control trial; obesity; pregnancy

\section{Introduction}

Gestational diabetes mellitus (GDM) is an important contributor to the unprecedented threat of Type 2 Diabetes (T2D) and obesity epidemic seen worldwide. Women with 
a previous diagnosis of GDM contribute substantially (up to 31\%) toward the total female population with diabetes [1]. Moreover, exposure to intrauterine hyperglycemia confers a future increased risk of T2D and cardiometabolic diseases in offspring of GDM mothers [2-4].

Although GDM can occur at any time during pregnancy, GDM is most often diagnosed in the late second trimester or early in third trimester between the 24th-28th gestational weeks, which coincides with markedly increased insulin resistance [5-8]. Maternal, fetal and neonatal consequences of GDM include pre-eclampsia, pre-term birth, excessive fetal growth and neonatal hypoglycemia $[9,10]$. Indeed, excessive fetal growth in GDM predates the usual time of GDM diagnosis with fetuses of obese women showing abnormal growth already by 20 weeks of gestation [11]. Currently, no randomized controlled trials have investigated the beneficial effects diagnosing GDM prior to 24-28 weeks of gestation [12,13]. However, early identification of GDM, at least in high-risk individuals, and subsequent treatment could improve obstetric and perinatal outcome [14].

Since their discovery, microRNAs (miRNAs) have been a focus of translational clinical research also in regards to the pathophysiology of GDM [15]. Endogenous miRNAs have a high stability in body fluids [16], which is partly attributed to their enclosure in extracellular vesicles [17], and they are accessible with minimal non-invasive sampling [18]. Furthermore, miRNAs are ideal biomarker candidates as technologies used for detection are specific and sensitive, and may be multiplexed [19]. By post-transcriptional gene regulation, miRNAs modulate various physiological processes and their dysregulation is often implicated in disease [20,21]. The placenta expresses more than 500 miRNA species [22,23] attributable in part by two placenta expressed miRNA clusters; the chromosome 19 and 14 miRNA clusters; C19MC and C14MC, respectively. Dysregulated placenta-associated miRNAs [24-27] as well as altered circulating miRNA profiles [28-43] have been associated with GDM, mirroring physiological and pathological changes during pregnancy.

There is an urgent need for early identification of women developing GDM later in pregnancy, ideally using affordable and effective biomarkers, with the objective to initiate treatment earlier. Ultimately, using these biomarkers could facilitate a reduction of the harmful effects of hyperglycemia on the mother and fetus. The aim of the current study was to investigate the utility of eight selected miRNAs as early non-invasive predictive biomarkers of GDM. The intention is to predict GDM development independently of confounding risk markers such as obesity, advanced maternal age and offspring sex.

\section{Materials and Methods}

\subsection{Participants}

In the complete DALI lifestyle study $(n=639)$ [44], obese pregnant women with a pre-pregnancy body mass index (BMI) of $\geq 29 \mathrm{~kg} / \mathrm{m}^{2}$, from across nine European countries were invited to participate if they were $\leq 19 \pm 6$ days of gestation (baseline), carried a singleton pregnancy, and were above 18 years. Women were excluded if they had preexisting diabetes, GDM at inclusion according to IADPSG/WHO2013 criteria (oral glucose tolerance test (OGTT), venous plasma glucose: fasting $\geq 5.1 \mathrm{mmol} / \mathrm{L}, 1 \mathrm{~h} \geq 10 \mathrm{mmol} / \mathrm{L}$, $2 \mathrm{~h} \geq 8.5 \mathrm{mmol} / \mathrm{L}$ ), an inability to walk $\geq 100 \mathrm{~m}$, chronic medical conditions or a psychiatric disorder. In women without GDM, the $75 \mathrm{~g}$ OGTT was repeated at 24-28 and 35-37 weeks and evaluated according to IADPSG/WHO2013 criteria [44].

Pregnant women for this nested case-control study were carefully age- and BMImatched from the DALI lifestyle study. The lifestyle interventions were shown not to impact obstetric outcome nor the development of GDM $[45,46]$. Additionally, pregnant women, who were diagnosed with GDM at baseline and thus excluded from entering the DALI study, were included in the current study (thus only baseline data available). GDM cases were classified according to the time of GDM diagnosis; early GDM (before 20 weeks of gestation; baseline) and late GDM (at 24-28 weeks of gestation), while controls were normal glucose tolerant (NGT) throughout pregnancy. GDM diagnosis at 35-37 weeks was not used in the current study. A flowchart of the study if provided in Figure S1. 


\subsection{Sample Collection and Storage}

Maternal clinical, biochemical and anthropometric assessment used in the current study have been previously described [44]. In brief, after a 10h overnight fast, blood samples were collected at baseline, prior to and during an OGTT. All samples were centrifuged and stored immediately at $-20^{\circ} \mathrm{C}$ or $-80^{\circ} \mathrm{C}$ before being processed in the ISO-certified central trial laboratory in Graz, Austria. Insulin concentrations were quantified using commercially available Enzyme-Linked Immuno Sorbent Assay (ELISAs) and insulin resistance was indirectly assessed using the homeostatic index of insulin resistance (HOMA-IR) index according to this formula: HOMA-IR $=[$ Fasting plasma insulin $(\mathrm{mU} / \mathrm{L}) \cdot$ Fasting plasma glucose $(\mathrm{mmol} / \mathrm{L})] / 22.5$ [47]. Quantitative insulin sensitivity check index (QUICKI): 1/[log fasting plasma glucose $(\mathrm{mg} / \mathrm{dL})+\log$ fasting plasma insulin $(\mu \mathrm{U} / \mathrm{mL})]$ [48]. Oral glucose insulin sensitivity (OGIS) index was derived from the OGTT using three formulas according to Mari et al. [49]. The Matsuda insulin sensitivity index [50] was calculated as follows: Matsuda $=10,000$ /square root of [(mean serum insulin $\cdot$ mean plasma glucose during OGTT) • (fasting plasma glucose • fasting serum insulin)]. Both HOMA-IR and QUICKI reflect the effects of insulin on hepatic glucose production (i.e., hepatic rather than peripheral insulin resistance) while the Matsuda index reflects whole body (hepatic and muscular) insulin sensitivity and the result obtained from the OGIS model reflects that of the hyperinsulinemic-euglyemic glucose clamp [51]. All other analytes were quantified by conventional chemistry methods.

\subsection{Small Non-Coding RNA Isolation and Analysis}

Eight small non-coding RNAs were pre-selected based on their reported association with GDM or features linked to a challenged metabolic profile (Table S1). Blood samples collected at baseline (average gestational age $15.1 \pm 2.4$ weeks, $n=123$ ) prior to the OGTT were used in this study.

Circulating total RNA was extracted from $250 \mu \mathrm{l}$ serum using TRI ${ }^{\circledR}$ Reagent LS (SigmaAldrich, Søborg, Denmark) according to manufacturers' protocol and with the addition of glycogen $(15 \mathrm{nmol})$ as a carrier and synthetic ath-miR-159 (0.25 pmol) as a spike-in control. RNA quantity and purity was determined by NanoDrop ND-100 spectrophotometer (ThermoFisher Scientific, Hvidovre, Denmark) with quality control performed on selected samples using Agilent Small RNA chips on the Agilent 2100 Bioanalyzer (Agilent Technologies, Glostrup, Denmark).

A total of $100 \mathrm{ng}$ serum RNA was reverse transcribed using miRNA specific stemloop RT primers and MultiScribe ${ }^{\mathrm{TM}}$ Reverse Transcription kit (ThermoFisher Scientific) according to manufacturers' protocol. Synthetic Caenorhabditis elegans (cel)-miR-39 was added ( $0.5 \mathrm{amol})$ as spike-in control for cDNA synthesis.

Diluted cDNA was mixed with appropriate primers and QuantiTect SYBR Green PCR master mix (Qiagen, Copenhagen, Denmark). All qPCR assays, in duplicates, were pipetted using an automated pipetting system consisting of two instruments; the PIRO ${ }^{\circledR}$ (Dornier-LTF, Germany) and epMotion ${ }^{\circledR} 96$ (Eppendorf Nordic, Hørsholm, Denmark), respectively. The 384-well plates were analyzed using the ViiA real time PCR System (ThermoFisher Scientific) and calibrated using an interplate-calibrator consisting of pooled sample material. Raw CT-values were normalized against the geometric mean of three reference genes; the endogenous small nuclear U6, ath-miR-159 and cel-miR-39. miRNA quantities were determined using the standard curve method, and subsequently expressed relative to the levels of the NGT group.

\subsection{Ethical Statement}

Written informed consent was obtained at baseline. The study was performed according to the Declaration of Helsinki II and local ethics committees approved the study. Trial registration was ISRCTN70595832. 


\subsection{Statistical Analysis}

Continuous variables were tested for normality of distribution, and log-transformed if skewed variables (BMI, miRNAs levels, variables pertaining to glucose metabolism as well as triglycerides and leptin levels) were used, where necessary, in subsequent analyses. Variables with approximately normal distribution are presented as mean \pm standard deviation (SD), and those with skewed distribution are presented as median and interquartile range (IQR). Continuous variables of women with a normal glucose tolerance were compared with those of women, who had either GDM at baseline (early GDM) or who developed GDM later (late GDM), using independent t-test with Bonferroni correction for multiple testing. Categorical variables were evaluated using $X^{2}$ test or Fishers' exact test. Mean adjusted levels were obtained from multiple linear regression models and compared between the three different groups, after adjustment for the following covariates: maternal BMI and age at baseline, gestational age and offspring sex.

Binary logistic regression for the association between GDM and miRNA were carried out with adjustment for potentially confounding variables. Results are represented by the odds ratio (OR) and 95\% confidence interval (CI). Receiver Operate Characteristic (ROC) curve analysis was performed and Area Under the Curve (AUC) was reported for individual and a combination of miRNAs.

Predicted target genes for the individual miRNAs were found using TargetScan (v.7.2, human, http:/ / www.targetscan.org/vert_72) [52] and pathway enrichment analysis was performed using the PANTHER (Protein ANalysis THrough Evolutionary Relationships) Classification System (v.15.0, http:/ / pantherdb.org) and the PANTHER pathways annotation set [53]. Enrichment analysis was visualized by RStudio (v. 1.3.1093, RStudio, PBC Boston, MA, USA, http:/ / www.rstudio.com) using the ggplots2 (v.3.1.0, https:/ /ggplot2.tidyverse.org) package [54].

A $p$-value of $<0.05$ was considered statistically significant. All analyses were conducted using SPSS, version 26.0 (SPSS Inc., Chicago, IL, USA) and graphical representation was done in GraphPad Prism vers. 9 (GraphPad Inc., La Jolla, CA, USA.). Graphical abstract was created with BioRender (Biorender.com).

\section{Results}

\subsection{Anthropometric Baseline Measurement of Study Participants}

Forty-one healthy pregnant, glucose tolerant women and 82 women with either an early ( $>20$ weeks of gestation) or a late (at 24-28 weeks of gestation) diagnosis of GDM were studied. Importantly, all of the participants were well-matched in terms of age, BMI, gestational age, parity, smoking status, ethnicity and their lipid profiles (Table 1). Women with an early diagnosis of GDM (early GDM) had higher fasting glucose, fasting insulin, higher insulin resistance and lower insulin sensitivity at baseline compared with women with a later diagnosis of GDM (late GDM) (Table 1). Before 20 weeks of gestation, higher glucose levels were observed in women with late GDM compared to women with NGT. There were no differences in offspring birthweight or sex.

Table 1. Baseline characteristics for anthropometric and clinical parameters of study participants measured prior to 20 gestational weeks.

\begin{tabular}{|c|c|c|c|c|c|c|}
\hline & $\begin{array}{c}\text { NGT } \\
(n=41)\end{array}$ & $\begin{array}{c}\text { Early GDM } \\
\quad(n=41)\end{array}$ & $\begin{array}{l}\text { Late GDM } \\
\qquad(n=41)\end{array}$ & $\begin{array}{l}\text { NGT vs. Early } \\
\text { GDM }\end{array}$ & $\begin{array}{l}\text { NGT vs. } \\
\text { Late GDM }\end{array}$ & $\begin{array}{l}\text { Early GDM vs. } \\
\text { Late GDM }\end{array}$ \\
\hline $\begin{array}{l}\text { Gestational age at } \\
\text { inclusion (weeks) }\end{array}$ & $15.2 \pm 2.4$ & $14.9 \pm 2.4$ & $15.3 \pm 2.5$ & 1.0 & 1.0 & 1.0 \\
\hline $\begin{array}{l}\text { Gestational age at } \\
\text { delivery (weeks) }\end{array}$ & $40.1 \pm 1.1$ & $39.3 \pm 1.7$ & $40 \pm 39.3$ & 0.17 & 0.67 & 0.92 \\
\hline Age (years) & $33.2 \pm 3.8$ & $33.7 \pm 4$ & $32.7 \pm 4$ & 1.0 & 1.0 & 0.73 \\
\hline BMI at inclusion $\left(\mathrm{kg} / \mathrm{m}^{2}\right)$ & $33.3(32.2-35.4)$ & $33.3(31.7-36.0)$ & $33.3(31.7-35.9)$ & 0.99 & 0.99 & 0.99 \\
\hline Waist circumference $(\mathrm{cm})$ & $107 \pm 10.7$ & $107.7 \pm 9.8$ & $105.6 \pm 8.8$ & 1.0 & 1.0 & 1.0 \\
\hline Neck circumference $(\mathrm{cm})$ & $36.0(35.2-37.0)$ & $36.0(34.5-38.0)$ & $35.5(34.6-36.9)$ & 0.58 & 0.58 & 0.58 \\
\hline Resting heart rate (RHR) & $79.7 \pm 11.3$ & $83.9 \pm 12.2$ & $80.0 \pm 9.3$ & 0.28 & 1.0 & 0.32 \\
\hline
\end{tabular}


Table 1. Cont.

\begin{tabular}{|c|c|c|c|c|c|c|}
\hline & $\begin{array}{c}\text { NGT } \\
(n=41)\end{array}$ & $\begin{array}{l}\text { Early GDM } \\
\quad(n=41)\end{array}$ & $\begin{array}{l}\text { Late GDM } \\
\quad(n=41)\end{array}$ & $\begin{array}{c}\text { NGT vs. Early } \\
\text { GDM }\end{array}$ & $\begin{array}{l}\text { NGT vs. } \\
\text { Late GDM }\end{array}$ & $\begin{array}{c}\text { Early GDM vs. } \\
\text { Late GDM }\end{array}$ \\
\hline Fasting glucose (mmol/L) & $4.7(4.3-4.8)$ & $5.2(5-5.6)$ & $4.9(4.6-5.2)$ & $<0.001$ & 0.024 & 0.002 \\
\hline 1h glucose $(\mathrm{mmol} / \mathrm{L})$ & $7.2(5.9-7.6)$ & $9.0(7.2-10.3)$ & $7.2(6.2-8.3)$ & $<0.001$ & 1.0 & 0.002 \\
\hline $2 \mathrm{~h}$ glucose $(\mathrm{mmol} / \mathrm{L})$ & $5.6(4.9-6.5)$ & $7.3(6.2-8.4)$ & $6.4(5.7-7.4)$ & $<0.001$ & 0.024 & 0.14 \\
\hline $\mathrm{HbA} 1 \mathrm{c}(\%)$ & $5.0(4.8-5.4)$ & $5.1(5-5.4)$ & $5.2(5.0-5.5)$ & 0.16 & 0.16 & 0.16 \\
\hline Fasting insulin $(\mu \mathrm{U} / \mathrm{mL})$ & $11.9(9.7-18.4)$ & $18.1(13.9-25.8)$ & $14.6(9.4-18.5)$ & 0.004 & 1.0 & 0.027 \\
\hline 1h insulin $(\mu \mathrm{U} / \mathrm{mL})$ & $95.2(57.5-161.1)$ & $127.7(66.2-173)$ & $95.8(52.5-175.5)$ & 0.45 & 0.45 & 0.45 \\
\hline $2 \mathrm{~h}$ insulin $(\mu \mathrm{U} / \mathrm{mL})$ & $52.2(34.5-88.1)$ & $92.4(58.4-153.7)$ & $59.8(46.9-100.7)$ & 0.001 & 0.59 & 0.078 \\
\hline HOMA-IR & $2.61(1.98-3.70)$ & $4.25(3.19-6.53)$ & $3.11(2.13-4.19)$ & $<0.001$ & 0.87 & 0.006 \\
\hline Quicki & $0.330 \pm 0.02$ & $0.309 \pm 0.021$ & $0.325 \pm 0.027$ & $<0.001$ & 0.94 & 0.005 \\
\hline OGIS $\left(\mathrm{ml} / \mathrm{min} / \mathrm{m}^{2}\right)$ & $424.9 \pm 56.9$ & $328.7 \pm 67.7$ & $385.1 \pm 52.8$ & $<0.001$ & 0.10 & 0.022 \\
\hline Matsuda & $2.98(2.3-4.4)$ & $2.1(1.0-3.0)$ & $2.83(2.1-3.9)$ & 0.061 & 1.0 & 0.61 \\
\hline Triglycerides (mmol/L) & $1.32(1.13-1.60)$ & $1.48(1.07-2.04)$ & $1.27(0.9-1.68)$ & 0.32 & 0.32 & 0.32 \\
\hline Free fatty acids (mmol/L) & $0.61 \pm 0.19$ & $0.62 \pm 0.22$ & $0.65 \pm 0.17$ & 1.0 & 1.0 & 1.0 \\
\hline $\begin{array}{l}\text { HDL cholesterol } \\
(\mathrm{mmol} / \mathrm{L}) \\
\text { LDL cholesterol }\end{array}$ & $1.46 \pm 0.23$ & $1.4 \pm 0.27$ & $1.49 \pm 0.26$ & 0.93 & 1.0 & 0.34 \\
\hline$(\mathrm{mmol} / \mathrm{L})$ & $3.16 \pm 0.81$ & $2.98 \pm 0.77$ & $3.32 \pm 0.75$ & 0.94 & 1.0 & 0.17 \\
\hline Leptin $(\mathrm{pg} / \mathrm{mL})$ & $36.0(25.2-46.1)$ & $31.9(23.1-43.6)$ & $38.9(29.5-47.3)$ & 0.53 & 0.53 & 0.53 \\
\hline \multicolumn{7}{|l|}{ Ethnicity (European/non- } \\
\hline Parity & & & & & & \\
\hline (Primipara/Multipara) & $18 / 23$ & $24 / 17$ & $26 / 15$ & 0.27 & 0.12 & 0.82 \\
\hline Previous GDM (No/Yes) & $32 / 1$ & $22 / 5$ & $21 / 0$ & 0.081 & 1.0 & 0.059 \\
\hline Smoking (No/Yes) & $37 / 4$ & $36 / 5$ & $36 / 5$ & 1.0 & 1.0 & 0.92 \\
\hline \multicolumn{7}{|l|}{ Offspring sex } \\
\hline Birthweight $(\mathrm{g})$ * & $3548 \pm 478$ & $3441 \pm 598$ & $3557 \pm 496$ & 1.0 & 1.0 & 1.0 \\
\hline
\end{tabular}

Data are presented as mean \pm standard deviations or median (interquartile range). NGT, Normal glucose tolerance. GDM gestational diabetes. Continuous data were analyzed by either one-way ANOVA followed by Bonferroni correction if data were normally distributed or Kruskal-Wallis test or Mann-Whitney test for non-normally distributed data. Categorical data were analyzed by Chi-Square test (2-sided) or Fisher's exact test. ${ }^{*} N=26$ for early GDM offspring as these women were excluded from the DALI trial and follow-up was not complete. Early GDM only had values for the OGTT at baseline, as these women were excluded in the complete DALI study. HOMA-IR: Homeostatic index of insulin resistance, QUICKI: Quantitative insulin sensitivity check index, OGIS: Oral glucose insulin sensitivity index, Matsuda: Matsuda insulin sensitivity index. Bold font indicates statistical significance.

\subsection{Non-Coding RNAs are Associated with GDM}

Eight pre-selected circulating non-coding miRNAs were measured at the DALI study baseline. Women, who were diagnosed with late GDM presented with elevated levels of miR-16-5p (mean difference 1.1, $p$-adjusted 0.008), miR-29a-3p (mean difference 0.7, $p$-adjusted 0.004), and miR-134-5p (mean difference 0.5, $p$-adjusted 0.046) compared with women who remained NGT throughout gestation (Figure 1A-C). Additionally, two miRNAs were significantly different between the two GDM groups with women with late GDM displaying higher levels of miR-16-5p (mean $1.1 \pm 1.1$, $p$-adjusted 0.008) and miR-122-5p (mean $0.9 \pm 1.1, p$-adjusted 0.046), respectively (Figure 1A,D).

Four additional miRNAs (miR-103-3p, -223-3p, -330-3p and 433-3p) had circulating levels with a gradual increase found in GDM cases although not significant upon correction for multiple comparisons (Figure S2A-D).

\subsection{Correlations between miRNAs and Clinical and Biochemical Phenotypes}

The relationship between circulating miRNAs and clinical variables measured at baseline as well as at 24-28 weeks and 35-37 weeks were investigated (Table 2). Among the selected miRNAs, miR-16-5p correlated positively with age $(r=0.203, p=0.029, n=116)$. Upon adjustment for confounding variables (gestational age, BMI and offspring sex) this correlation increased ( $\left.\mathrm{r}_{\mathrm{adj}}=0.221, p_{\mathrm{adj}}=0.028, n=97\right)$. In response to a 2-h OGTT, intermediate 1-h glucose values measured at baseline or at 24-28 weeks correlated with miR$29 \mathrm{a}-3 \mathrm{p}(\mathrm{r}=0.191, p=0.040, n=116)$ and miR-16-5p $(\mathrm{r}=0.256, p=0.023, n=79)$ respectively. 

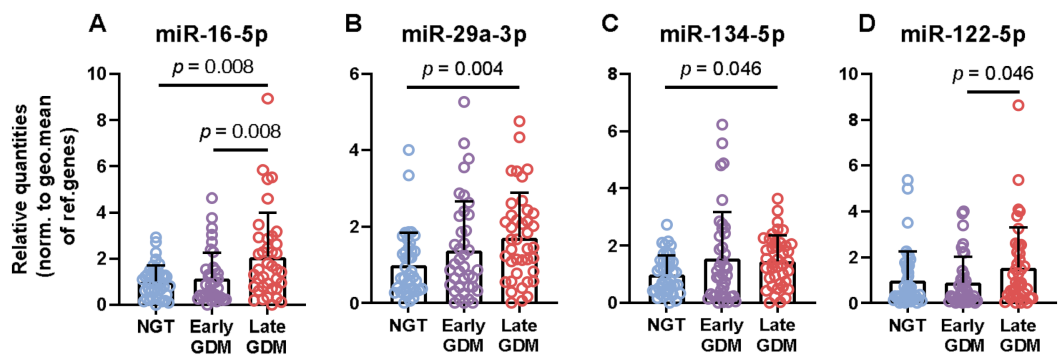

Figure 1. Circulating miRNAs are elevated in late GDM cases. Relative mean quantities with standard deviations of serum microRNAs expressed in the three groups (A-D). Data were normalized against the geometric mean of snRNA U6, ath-miR-159 and c.el.miR-39. All indicated $p$-values were determined by independent $\mathrm{t}$-test on logarithmic transformed data with Bonferroni correction for multiple comparisons.

Table 2. Significant Pearsons correlations between clinical variables and circulating miRNAs.

\begin{tabular}{|c|c|c|c|c|}
\hline & $\operatorname{miR}-29 a-3 p$ & $\operatorname{miR}-134-5 p$ & $\operatorname{miR}-16-5 p$ & $\operatorname{miR}-122-5 p$ \\
\hline Age $^{a}$ & 0.133 & 0.114 & $0.203 *$ & 0.077 \\
\hline 1h glucose ${ }^{a}$ & $0.191 *$ & 0.101 & $0.256^{*, \mathrm{~b}}$ & 0.136 \\
\hline $2 \mathrm{~h}$ glucose ${ }^{\mathrm{b}}$ & $0.266 *$ & $0.226^{*}$ & $0.345 * *$ & 0.069 \\
\hline $\mathrm{HbA1} \mathrm{c}^{\mathrm{b}}$ & 0.211 & 0.044 & $0.259 *$ & 0.016 \\
\hline Matsuda index ${ }^{b}$ & 0.125 & 0.131 & 0.082 & $-0.309 *$ \\
\hline Insulin sensitivity (OGIS) ${ }^{b}$ & -0.040 & 0.016 & -0.054 & $-0.437^{* *}$ \\
\hline Triglycerides $^{\text {a }}$ & -0.088 & -0.106 & -0.197 * & 0.030 \\
\hline Free fatty acids a & $0.186 *$ & 0.059 & -0.006 & 0.034 \\
\hline HDL cholesterol ${ }^{c}$ & -0.085 & -0.091 & -0.106 & $-0.240 *$ \\
\hline Leptin $^{c}$ & 0.102 & 0.132 & 0.058 & $-0.236^{*}$ \\
\hline Birthweight & 0.061 & 0.068 & 0.047 & $0.243 *$ \\
\hline $\operatorname{miR}-134-5 p^{a}$ & $0.731 * * *$ & - & - & - \\
\hline miR-16-5p a & $0.487 * * *$ & 0.181 & - & - \\
\hline miR-122-5p & 0.173 & 0.050 & $0.343 * * *$ & - \\
\hline
\end{tabular}

Table 2 Association between clinical variables and circulating miRNAs. Clinical variables were measured at baseline $^{\mathrm{a}}$, at $24-28$ week $^{\mathrm{b}}$, or at $35-37$ week $^{\mathrm{c}}$ and correlated with baseline miRNA levels. Pearson correlation coefficients are listed. Statistically significant values are in bold with $p$ values, ${ }^{*} p<0.05,{ }^{* *} p<0.01$ and ${ }^{* * *} p<0.001$ Levels of miRNAs were normalized against the geometric mean of snRNA U6, ath-miR-159 and c.el.miR-39 and logarithmic transformed prior to analysis. Covariate were maternal age and BMI, gestational age and offspring sex.

Three miRNAs (miR-29a-3p, -134-5p and -16-5p) correlated with 2-h fasting glucose levels measured at 24-28 weeks of gestation, and the degree of correlation increased after adjustment for maternal age and BMI, gestational age and offspring sex (miR-29a-3p, $\mathrm{r}_{\mathrm{adj}}=0.325, p_{\text {adj }}=0.004, \mathrm{miR}-16-5 \mathrm{p}, \mathrm{r}_{\mathrm{adj}}=0.368, p_{\text {adj }}=0.001, \mathrm{miR}-134-5 \mathrm{p}, \mathrm{r}_{\mathrm{adj}}=0.241$, $\left.p_{\text {adj }}=0.033\right)$. Glycated hemoglobin $(\mathrm{HbA1c})$ measured at $24-28$ weeks correlated with baseline miR-16-5p $(r=0.259, p=0.031, n=69)$. A negative association between insulin sensitivity through the OGIS index and miR-122-5p was observed $(\mathrm{r}=-0.437, p=0.004$, $\left.\mathrm{r}_{\mathrm{adj}}=-0.499, p_{\mathrm{adj}}=0.002\right)$. Other measurements of insulin sensitivity such as the Matsuda index also showed negative correlation with miR-122-5p. Of note, HOMA-IR was not correlated with the selected miRNAs. Both HDL cholesterol $(\mathrm{r}=-0.240, p=0.043, n=72)$ and leptin ( $\mathrm{r}=-0.236, p=0.036, n=79)$ levels were negatively correlated with miR-122-5p. Birthweight was positively associated with miR-122-5p $\left(\mathrm{r}=0.243, p=0.013, \mathrm{r}_{\mathrm{adj}}=0.237\right.$, $\left.p_{\text {adj }}=0.018\right)$. All of the miRNAs correlated to various degrees with each other.

\subsection{Classification of GDM Cases Using Serum miRNAs}

To evaluate the performance of serum miRNAs as predictive biomarkers for GDM, i.e., comparing women with NGT with late GDM, ROC curves were constructed using the miRNAs, which were different between the two groups (Figure 2A-C). When assessing 
individual miRNAs, the discriminatory capability of miR-29a-3p and miR-16-5p had the highest area under the curves (AUCs) of 0.698 (sensitivity of $72.5 \%$ and specificity of $57.5 \%, p=0.002$ ) and 0.687 (sensitivity of $60.5 \%$ and specificity of $57.5 \%, p=0.005$ ), respectively. This was followed by miR-134-5p with an AUC of 0.654 (sensitivity of $65.0 \%$ and a specificity of $51.2 \%, p=0.017)$.
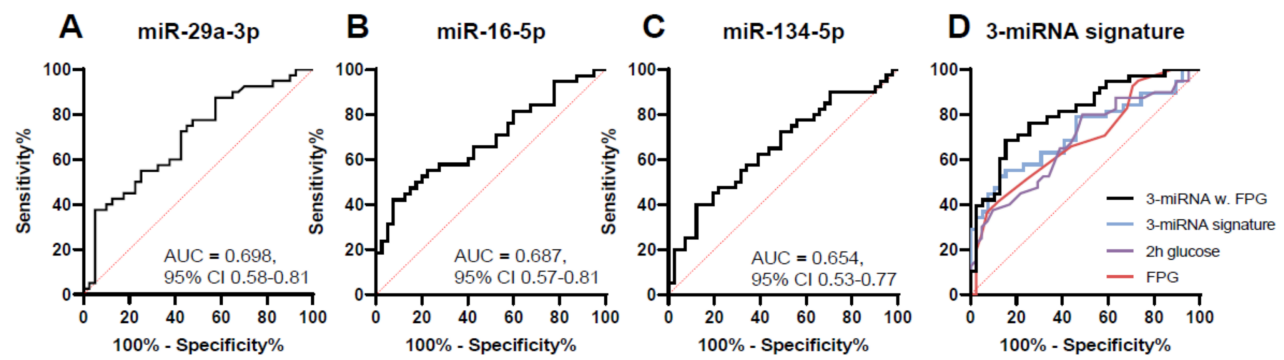

Figure 2. Predictive capabilities of circulating miRNAs. ROC curves based on miRNA levels. Shown are the three miRNAs distinguishing between GDM cases diagnosed later in pregnancy and NGT cases (A-C) as well as a combination of these miRNAs ((D) 3-miRNA signature, miR-16-5p, -29a-3p and -134-5p, AUC = 0.717, 95\% CI 0.60-0.83). Fasting plasma glucose (FPG, AUC $=0.687,95 \%$ CI 0.57-0.80) and 2-h glucose value (2h glucose, AUC $=0.681,95 \%$ CI $0.57-0.80$ ) were evaluated alone or in combination with the 3-miRNA signature.

Using binary logistic regression, three (miR-16-5p, -29a-3p and -134-5p) miRNAs were incorporated into a 3-miRNA-signature increasing the AUC to 0.717 (sensitivity of $63.2 \%$ and specificity of $66.7 \%, p=0.001$ ) (Figure 2D). In comparison, clinically accepted glucose values such as baseline FPG or $2 \mathrm{~h}$ glucose values as predictors of GDM had AUCs of 0.687 (sensitivity of $65.0 \%$ and specificity of $61.0 \%, 95 \%$ CI $0.56-0.80$ ) and 0.681 (sensitivity of $65.9 \%$ and specificity of $56.1 \%, 95 \%$ CI $0.57-0.80$ ), respectively. The 1 h glucose and $\mathrm{HbA} 1 \mathrm{c}$ values were not able to distinguish late GDM cases from NGT (Figure S3C) at baseline at least. If the 3-miRNA-signature was combined with FPG an additional increase in the AUC to 0.81 was observed (sensitivity of $68.4 \%$ and specificity of $82.1 \%$, 95\% CI 0.71-0.90) (Figure 2D). Increased discriminatory power was also observed when the 3-miRNA signature was combined with $2 \mathrm{~h}$ glucose values (AUC $=0.764,95 \% \mathrm{CI}$ $0.65-0.88$, data not shown).

We also investigated if risk markers previously identified in the DALI study would improve the predictive power of our 3-miRNA signature. If maternal resting heart rate (RHR), neck circumference or maternal height were added individually to the 3-miRNA signature equal increases in the AUC was seen (AUC 0.727, 95\% CI 0.61-0.84, data not shown).

The effects of the individual miRNAs or a combination hereof on the likelihood of being diagnosed with GDM were investigated using logistic regression. With a one-unit increase in miR-29a-3p, the odds ratio of being diagnosed with GDM was 2.5 (95\% CI $1.3-4.5, p=0.003)$, while both miR-16-5p and miR-134-5p was associated with odds ratios of 1.9 (95\% CI 1.2-3.1, $p=0.006$ ) and 1.9 (95\% CI 1.1-3.5, $p=0.027$ ) respectively (Figure 3). At baseline, miR-122-5p levels did not affect the odds ratio of a GDM diagnosis (OR 1.2, $95 \%$ CI $0.9-1.6, p=0.17$ ). The combined 3-miRNA signature had an odds ratio of a GDM diagnosis of 85.5 (95\% CI 5.89-1248.1, $p=0.001$ ) with larger confidence intervals resembling the range of plausible odds ratios, when the three miRNAs are combined. Importantly, addressing potential confounding effects of maternal age and BMI as well as offspring sex did not alter the increased odds ratio of GDM with either miRNA (Figure 3).

Analyzing whether individual miRNAs could be used for diagnosing GDM cases at baseline resulted in modest AUCs (Figure S3A, Table S2). However, two miRNAs, miR-16$5 p$ and miR-122-5p were able to distinguish between women, who were diagnosed with GDM at baseline compared to those diagnosed at a later time in pregnancy (Figure S3B). 


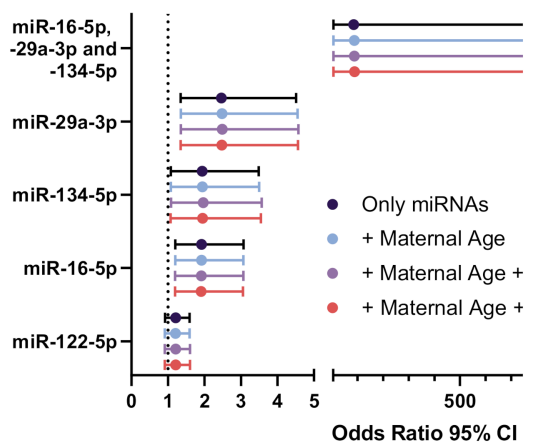

Figure 3. Odds ratios for the association of miRNAs with GDM. Odds ratio plot showing the predictive effects of either a single miRNA, a combination of these, or miRNAs after adjustment for confounding variables such as maternal age and BMI and offspring sex on GDM diagnosis. Normal glucose tolerant women were compared to women who were diagnosed with GDM later in pregnancy $(N=77-81)$. BMI: Body mass index.

\subsection{Predicted Targets and Pathway Analysis}

Key to understanding the potential role of the identified miRNAs in relation to GDM is to investigate, which predicted targets and pathways are affected. A total of 1890 unique target transcripts were identified with the majority of them linked to miR-29a-3p targets. No overlap between the in silico predicted targets and all four miRNAs were observed. However, 148 targets were common between two or more miRNAs (Figure 4A).

A

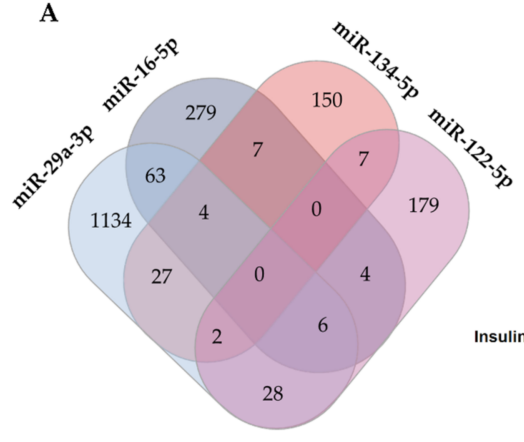

B

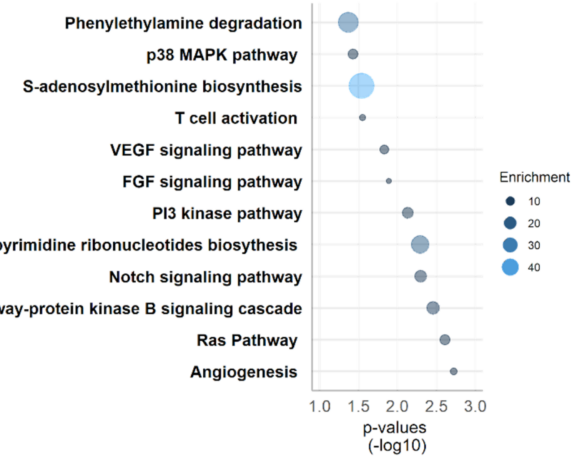

Figure 4. Predicted targets and pathway enrichment analysis. Predicted targets of the four differentially expressed miRNAs associated with GDM. (A) Venn diagram of predicted targets identified through TargetScan v.7.2. (human). (B) Enrichment analysis of predicted targets common to two or more miRNAs. The size and the color of the circle corresponds to the fold enrichment.

Pathways associated with vascular endothelial growth factor (VEGF)-, fibroblast growth factor (FGF)-, phosphoinositide (PI)-3 kinase-, Notch- and insulin signaling were all positively enriched by more than 4.5 -fold (Figure $4 \mathrm{~B}$ ). The biosynthesis of S-adenosylmethio nine was the most enriched pathway by 45 -fold $(p=0.028)$ due to the methionine adenosyltransferase 2A (MAT2A) transcript which is a predicted target of both miR-29a-3p and 134-5p. Predicted target genes in the enriched pathways are all listed in Table S3.

\section{Discussion}

Currently, there are no good predictive biomarkers for the development of GDM. In this study, overweight and obese women who were NGT at baseline but diagnosed with GDM at 24-28 weeks of gestation had elevated miR-16-5p, -29a-3p and -134-5p levels already prior to 20 week of gestation. Furthermore, a combination of the three miRNAs into a 3-miRNA signature (miR-16-5p, -29a-3p and -134-5p) showed high predictive discriminatory power comparable with clinical accepted glucose values (FPG, 1-h and 2-h 
glucose values after an OGTT). Additionally, miRNA expressions were associated with increased odds ratios of GDM.

Consistent with our results, elevated circulating miR-16-5p was also shown by Zhu et al. [55] using peripheral blood collected from Chinese women early in pregnancy (16-19 weeks of pregnancy), although ROC was not constructed. Additionally, fetal macrosomia was also associated with elevated plasma levels of miR-16-5p collected between $18-28$ weeks of gestation [56]. In our nested case-control study, both miR-16-5p and miR-29a-3p was also associated with macrosomia (Figure S4).

In support of our study, the temporal profile of plasma miR-16-5p measured at 16-20 weeks, 20-24 weeks and 24-28 weeks' of gestation in Chinese women gradually increased throughout pregnancy [57]. Absolute values of plasma miR-16-5p at 24-28 weeks of gestation clearly distinguished between GDM cases and controls (with cut-off $>2554$ copies, sensitivity $41.6 \%$ and specificity $95.8 \%$ ) [57]. However, Cao et al. did not investigate the utility of miR-16-5p for early identification of GDM in their study [57]. Two other studies investigated the expression of miR-16-5p in third-trimester samples of maternal leukocytes from Turkish pregnant women with pre-eclampsia and GDM [32] or from pregnant women with polycystic ovary syndrome and GDM [31]. They showed no differences in the expression of miR-16-5p between the different groups. Of note, the GDM and control group in the two Turkish studies [31,32] were the same. Similarly, no differences in miR-16$5 p$ levels were observed from second-third trimester serum samples from Mexican women with GDM [34] or serum sampled over a large part of gestation (13-31 weeks, median; 27 weeks) from South African women with GDM [42]. Discrepancies between studies could be due to sampling period, sampling type and ethnicity. It is also worth considering advanced maternal age as a confounder as this is associated with an increased risk of GDM [9]. It has been suggested that miRNA levels might also change in an age-dependent fashion. Indeed, in this study maternal age positively correlated with miR-16-5p in this study. Despite this, miR-16-5p was still associated with increased odds ratios of GDM after adjusting for maternal age. Of note, miR-16 is highly abundant in erythrocytes, and an upregulation of miR-16 has been associated with hemolysis [58]. However, no visual signs of hemolysis were observed in our samples.

While circulating miR-29a is increased in type 2 diabetes patients [59] few studies have investigated miR-29a in relation to GDM $[33,34,37]$. Consistent with our study, serum levels of miR-29a-3p obtained at 18-23 weeks of gestation was found to be higher in Mexican women with GDM according to the IADPSG criteria [34]. In white non-Hispanic women with a male offspring, circulating miR-29a-3p obtained at 7-23 weeks of gestation was associated with an increased risk of GDM [38]. We did not observe a sex-dependent expression of miR-29a-3p (Figure S5). By contrast, miR-29a was found decreased in serum collected from Chinese women at 16-19 gestational weeks compared to controls [33]. Moreover, since increased levels of miR-29a have also been related with both preeclampsia and gestational hypertension $[28,60]$, it would be relevant to investigate whether miR-29a could be of use as a general prognostic factor for complicated pregnancies.

The exact cellular sources of the circulating miR-29a-3p, studied here as another early pregnancy GDM risk marker, are not known. In the current study, we did not evaluate to which degree the content of circulating exosomes contributed to the individual miRNA levels. However, extracellular vesicle miR-29a content is increased in women with GDM [28]. Additionally, a greater increase in circulating placenta-derived exosomes across gestation was observed in GDM pregnancies compared to normal pregnancies [61]. Further, consistent patterns of selected miRNAs were demonstrated across placenta-derived exosomes, plasma exosomes and placenta exosomes isolated from GDM pregnancies [41].

Liver [62], skeletal muscle [63], beta cell [64] and adipose tissue [65] miR-29a levels are increased in states of insulin resistance and hyperglycemia. Accordingly, circulating miR-29a decreases upon metformin treatment [66]. Therefore, it is conceivable that the increased early pregnancy miR-29a levels, as well as the other differentially expressed miRNAs in women who later develop GDM, could be an indicator of a general impaired 
metabolic state. MiR-29a along with miR-134 is predicted to target Methionine Adenosyltransferase 2A (MAT2A). Inhibition of MAT2A by miR-29a and miR-134, and deficiency of S-adenosylmethionine (SAM) in pregnancy could have implications for fetal programming, because SAM constitutes the required methyl donor in epigenetics [67].

Predicted mRNA targets of the four miRNAs showed significant enrichment of pathways related to feto-placental development, such as VEGF signaling and angiogenesis [68], the insulin/insulin-like growth factor (IGF) signaling pathway [69], as well as development in general (p38MAPK pathway, FGF signaling, PI3 kinase pathway, Ras pathway and Notch signaling). Moreover, one-carbon metabolic pathways related to fetal programming and epigenetics such as SAM biosynthesis and de novo pyrimidine ribonucleotides biosynthesis [70] are also predicted targets by the altered miRNAs. In addition, pathways related to the innate (phenylethylamine degradation) and adaptive immune system ( $\mathrm{T}$ cell activation) were also predicted targets of the GDM-associated circulating miRNAs, suggesting possible moderation of placental immune tolerance by these miRNAs [71]. Thus, important pathways related to fetal development, epigenetic programming and the immune system could be altered by the miRNAs increased in the maternal circulation in GDM.

Comprehensive profiling of maternal and fetal circulating miRNAs demonstrated elevation in pregnant women and cord blood of miR-134-5p. It belongs to the chromosome 14 miRNA cluster and is highly expressed in placenta tissue [72]. After birth, localization of miR-134-5p is restricted to the brain [73]. In line with our finding, hyperglycemia induces $\mathrm{miR}-134-5 \mathrm{p}$ expression in endothelial progenitor cells and overexpression of miR-134-5p results in impaired tube formation and cell migration [74]. In our study, we observed elevated levels of miR-134-5p at baseline in those women, who were diagnosed with GDM later in pregnancy. Interestingly, in primary feto-placental endothelial cells (fpEC) isolated from obese women with GDM, miR-134-5p showed a sex-dependent regulation in women carrying female offspring [27]. However, we were not able to confirm a sex-dependent expression of our selected circulating miRNAs (Figure S5). Fetal sex may influence the risk of GDM [75]. Hence, we adjusted for offspring sex. However, in clinical practice this covariate would often not be used despite the fact that the sex of the fetus can be known with high certainty at the mid-pregnancy ultrasound scans.

Additionally, miR-134-5p has also been associated with the progression of pre-eclamps ia [76] and with the inhibition of trophoblast cell infiltration [77]. Tumor necrosis factor alpha (TNF- $\alpha$ ), a cytokine produced in the placenta and adipose tissue, is elevated in late pregnancy and associated with insulin resistance [78]. Induction of miR-134-5p, by TNF- $\alpha$, has been observed [79] and suggests a potential role for miR-134-5p in insulin-mediated glucose disposal and insulin sensitivity.

The women included in this study were all overweight/obese with GDM diagnosed around 24-28 gestational weeks showing elevated levels of the liver-enriched miR-122-5p already at baseline. This result is in line with the study by Gillet et al. which showed that pregnancies affected by GDM were associated with elevated serum exosomal miR-122 early in gestation (6-15 weeks of gestation) [28]. Several studies have shown that increased miR-122 is associated with obesity, insulin resistance, metabolic syndrome [80-82], while metformin treatment [66] and weight loss [83] results in a reduction of miR-122-5p. We demonstrate in our study that insulin sensitivity, measured through OGIS, and HDL cholesterol were negatively correlated with miR-122-5p, while offspring birthweight was positively correlated with miR-122-5p, thus further strengthening the role of miR-122 as a marker of impaired metabolic health.

In contradiction to our study, Carreras-Badosa et al. found that maternal pre-gestational obesity and gestational weight gain were associated with decreased levels of second trimester (24-32 weeks of gestation) plasma miR-122-5p [36]. Moreover, a recent study on intrauterine fetal programming and GDM showed decreased circulating maternal and fetal miR-122-5p in a GDM rat model [84]. The reason for these discrepancies is not known, 
but could be due to differences in ethnicity of patients and interspecies differences in miRNA regulation.

The current IADPSG/WHO criteria have not been validated for use early in pregnancy. In the full DALI study, the majority of women, diagnosed with GDM before 20 weeks of gestation were identified by increased fasting glucose and found to exhibit features of the metabolic syndrome compared with women with normal glucose tolerance at baseline [85]. Despite an observed mild hyperglycemic state at baseline in the early GDM group retrospectively, it was speculated whether the diagnostic threshold for the full DALI study should have been higher thus including more of the early GDMs in the study [85]. It is recognized that considerable heterogeneity exists between women with GDM [86-88]. Phenotypical intergroup differences could, therefore, partly explain why most of the miRNAs in our study in the early GDM and NGT groups were similar and distinct from those women developing GDM de novo later in pregnancy.

Other potential biomarker candidates for early diagnosis of GDM, for prediction of GDM development $>24$ weeks of gestation and independent risk factors of GDM have been evaluated in the DALI study. These include plasma-glycated CD59 (pGCD59) [89], glycated hemoglobin $(\mathrm{HbA1c})$ [90] and non-modifiable, clinical characteristics such as maternal resting heart rate (RHR), neck circumference and height [91]. Plasma-GCD59 obtained before 20 weeks of gestation showed moderate prognostic value for identifying women who would develop GDM later in pregnancy (AUC $=0.68,95 \% \mathrm{CI}, 0.64-0.73$, $n=77$ ) [89]. Moderate predictive value was partly ascribed to the need of some degree of hyperglycemia for glycation of pGCD59 to happen [89]. Post hoc analysis of HbA1c within the entire DALI study (AUC 0.55) [90], and in our nested study (AUC 0.60, $p=0.16$ ) showed poor sensitivity for detecting GDM at any time in pregnancy. However, combing FPG with the 3-miRNA signature resulted in a higher AUC, as well as higher sensitivity and specificity. This is in agreement with a recent study by Hoorn et al. [92] who concluded that the best performing prognostic model for early prediction of GDM includes both clinical characteristics and early glucose measurements.

A limitation of the current study is that only selected miRNAs were investigated and other potential GDM prediction biomarkers could have been missed. Another caveat is that the DALI study only included high-risk overweight/obese women of largely European descent. Although obesity is a major risk factor of GDM, other factors such as insulin secretory defects contribute to the development of GDM which is evident among women with normal BMI. Despite these limitations, the results of this study suggest that a combination of circulating miRNAs measured before 20 weeks of gestation can predict incident GDM diagnosed between 24-28 weeks of gestation.

The findings in the present study needs to be validated in larger independent cohorts. Preferentially, the predictive utility of the 3-miRNA signature combined with early glucose measurements should be evaluated in both lean and obese women. For miRNAs to be used routinely in the clinic, they need to perform better than the current accepted glucose values, as well as be cost-effective with high-throughput. Additionally, they should not be influenced by the fasting-state of the woman.

\section{Conclusions}

This study provides evidence to justify future evaluation of circulating miRNAs early in pregnancy and their potential as screening/predictive biomarkers. The importance of identifying biomarkers that are not influenced by confounding variables and type of laboratory method capable of identifying women at risk of GDM early in pregnancy is clearly valuable and would greatly improve preventive strategies. Here, we identify three miRNAs (miR-16-5p, -29a-3p and miR-134-5p) in high-risk individuals as being elevated in early pregnancy in women who develop GDM. These miRNAs both individually and in combination are associated with higher odds of GDM. Early identification of GDM would most likely improve short-term pregnancy outcomes. It would be of interest to investigate if these miRNAs are already increased before pregnancy. 
Supplementary Materials: The following are available online at https:/ /www.mdpi.com/2073-440 9/10/1/170/s1, Figure S1: Study flow chart, Figure S2: Circulating small RNAs in GDM cases and controls, Figure S3: Receiver Operating Characteristic Curves in GDM cases and healthy pregnant controls, Figure S4: Association of miR-16-5p and miR-29a-3p with fetal macrosomia and Figure S5: Sex differences between the selected miRNAs, Table S1: Small RNAs and their association with GDM and primers used in the study, Table S2: Receiver Operate Curve characteristics, Table S3: Predicted enriched genes and pathways linked to GDM and miR-16-5p, -29a-3p, 122-5p and 134-5p.

Author Contributions: Conceptualization, A.E.S., M.N.M.v.P., G.D., P.D., D.M.J. and L.T.D.; Data curation, A.E.S. and M.N.M.v.P.; Formal analysis, A.E.S., M.N.M.v.P. and P.D.; Funding acquisition, A.E.S., G.D., P.D., D.M.J. and L.T.D.; Investigation, A.E.S., M.N.M.v.P. and L.T.D.; Methodology, A.E.S., M.N.M.v.P., G.D., P.D., D.M.J. and L.T.D.; Supervision, G.D., P.D. and L.T.D.; Visualization, A.E.S. and L.T.D.; Writing-original draft, A.E.S., M.N.M.v.P., G.D., P.D., D.S., D.M.J. and L.T.D.; Writing-review \& editing, M.N.M.v.P., G.D., P.D., D.S., D.M.J. and L.T.D. All authors have read and agreed to the published version of the manuscript.

Funding: This research was funded by the doctoral research grant from the Danish Diabetes Academy (DDA) supported by the Novo Nordisk Foundation and from Roskilde University to AES. A visiting professorship grant from the Danish Diabetes Academy, which is funded by the Novo Nordisk Foundation, grant number NNF17SA0031406 to GD. The DALI project has received funding from the European Community's 7th Framework Program (FP7/2007-2013) under grant agreement no 242187.

Institutional Review Board Statement: The study was conducted according to the guidelines of the Declaration of Helsinki, and approved by the relevant ethical committees before the start of DALI (NRES Committee East of England-Norfolk: 11/EE/0221; Medical University Poznan: 1165/12; UZ KU Leuven: ML7625; VUmc Amsterdam: 2012/400; Hospital De La Santa Creu i Sant Pau Barcelona 13/006(OBS); Medical University Vienna: 2022/2012-1369/2013; Region Hovedstaden Copenhagen: H-4-2013-005; Provinceof Padua: $4201 \times 11$; Galway University Hospitals: 7/12).

Informed Consent Statement: Informed and written consent was obtained from all subjects involved in the study.

Data Availability Statement: The raw data supporting the conclusions of this manuscript will be made available by the authors, without undue reservation, on request to the corresponding author.

Acknowledgments: We wish to thank the DALI Core Investigator Group and DALI consortium for their contribution; from data collection to their assistance in writing the manuscript. Frank Snoek and Dirk Timmerman are acknowledged for their participation as part of the DALI Core Investigator Group. Marija Petkovic is acknowledged for her assistance with the graphical abstract and Christa Persson for technical assistance.

Conflicts of Interest: The authors declare no conflict of interest. The funders had no role in the design of the study; in the collection, analyses, or interpretation of data; in the writing of the manuscript, or in the decision to publish the results.

Members of the DALI Core Investigator Group: Gernot Desoye (Project Coordinator, Austria, gernot.desoye@medunigraz.at), David Simmons (Trial Coordinator, UK, Da.Simmons@westernsydney. edu.au), Rosa Corcoy (Spain, RCorcoy@santpau.cat), Juan M. Adelantado Perez (Spain, adelantadojm@gmail.com), Alexandra Kautzky-Willer (Austria, alexandra.kautzky-willer@meduniwien.ac.at), Juergen Harreiter (Austria, juergen.harreiter@meduniwien.ac.at), Peter Damm (Denmark, pdamm@da dlnet.dk), Elizabeth Mathiesen (Denmark, elisabeth.reinhardt.mathiesen@regionh.dk), Dorte M. Jensen (Denmark, Dorte.Moeller.Jensen@rsyd.dk), Lise Lotte T. Andersen (Denmark, lise.lotte.anderse n@rsyd.dk), Fidelma Dunne (Ireland, fidelma.dunne@nuigalway.ie), Annunziata Lapolla (Italy, annunziata.lapolla@unipd.it), Maria G. Dalfra (Italy, mariagrazia.dalfra@aulss6.veneto.it), Alessandra Bertolotto (Italy, alessandrabertolotto1959@yahoo.it), Mireille van Poppel (Netherlands, mireille.vanpoppel@uni-graz.at), Judith G.M. Jelsma (Netherlands, j.jelsma@amsterdamumc.nl), Sander Galjaard (Netherlands, s.galjaard@erasmusmc.nl), Ewa Wender-Oegowska (Poland, ewaoz@post.pl), Agnieszka Zawiejska (Poland, agazaw@post.home.pl), David Hill (Lawson Switzerland, David.Hill@law sonresearch.com), Roland Devlieger (Belgium, roland.devlieger@uzleuven.be). 


\section{References}

1. Cheung, N.W.; Byth, K. Population Health Significance of Gestational Diabetes. Diabetes Care 2003, 26, 2005-2009. [CrossRef] [PubMed]

2. Clausen, T.D.; Mathiesen, E.R.; Hansen, T.; Pedersen, O.; Jensen, D.M.; Lauenborg, J.; Damm, P. High prevalence of type 2 diabetes and pre-diabetes in adult offspring of women with gestational diabetes mellitus or type 1 diabetes: The role of intrauterine hyperglycemia. Diabetes Care 2008, 31, 340-346. [CrossRef] [PubMed]

3. Malcolm, J.C.; Lawson, M.L.; Gaboury, I.; Lough, G.; Keely, E. Glucose tolerance of offspring of mother with gestational diabetes mellitus in a low-risk population. Diabet. Med. 2006, 23, 565-570. [CrossRef] [PubMed]

4. Boerschmann, H.; Pflüger, M.; Henneberger, L.; Ziegler, A.G.; Hummel, S. Prevalence and predictors of overweight and insulin resistance in offspring of mothers with gestational diabetes mellitus. Diabetes Care 2010, 33, 1845-1849. [CrossRef] [PubMed]

5. American Diabetes Association Standards of Medical Care in Diabetes-2015 Abridged for Primary Care Providers. Clin. Diabetes 2015, 33, 97-111. [CrossRef] [PubMed]

6. Metzger, B.E.; Gabbe, S.; Persson, B. International Association of Diabetes and Pregnancy Study Groups Recommendations on the Diagnosis and Classification of Hyperglycemia in Pregnancy. Diabetes Care 2010, 33, 676-682. [CrossRef]

7. National Institutes of Health. Diagnosing gestational diabetes mellitus. In Proceedings of the NIH Consensus Development Conference Statement, Bethesda, MD, USA, 4-6 March 2013.

8. World Health Organization. Diagnostic Criteria and Classification of Hyperglycaemia First Detected in Pregnancy; WHO: Geneva, Switzerland; pp. 1-63.

9. McIntyre, H.D.; Catalano, P.; Zhang, C.; Desoye, G.; Mathiesen, E.R.; Damm, P. Gestational diabetes mellitus. Nat. Rev. Dis. Prim. 2019, 5, 47. [CrossRef] [PubMed]

10. Filardi, T.; Tavaglione, F.; Di Stasio, M.; Fazio, V.; Lenzi, A.; Morano, S. Impact of risk factors for gestational diabetes (GDM) on pregnancy outcomes in women with GDM. J. Endocrinol. Invest. 2018, 41, 671-676. [CrossRef]

11. Sovio, U.; Murphy, H.R.; Smith, G.C.S. Accelerated Fetal Growth Prior to Diagnosis of Gestational Diabetes Mellitus: A Prospective Cohort Study of Nulliparous Women. Diabetes Care 2016, 39, 982-987. [CrossRef]

12. McIntyre, H.D.; Sacks, D.A.; Barbour, L.A.; Feig, D.S.; Catalano, P.M.; Damm, P.; McElduff, A. Issues with the Diagnosis and Classification of Hyperglycemia in Early Pregnancy. Diabetes Care 2016, 39, 53-54. [CrossRef]

13. Egan, A.M.; Hod, M.; Mahmood, T.; Dunne, F.P. Perspectives on diagnostic strategies for hyperglycaemia in pregnancy-Dealing with the barriers and challenges: Europe. Diabetes Res. Clin. Pr. 2018, 145, 67-72. [CrossRef]

14. Immanuel, J.; Simmons, D. Screening and Treatment for Early-Onset Gestational Diabetes Mellitus: A Systematic Review and Meta-analysis. Curr. Diab. Rep. 2017. [CrossRef] [PubMed]

15. Filardi, T.; Catanzaro, G.; Mardente, S.; Zicari, A.; Santangelo, C.; Lenzi, A.; Morano, S.; Ferretti, E. Non-Coding RNA: Role in Gestational Diabetes Pathophysiology and Complications. Int. J. Mol. Sci. 2020, 21, 4020. [CrossRef] [PubMed]

16. Chen, X.; Ba, Y.; Ma, L.; Cai, X.; Yin, Y.; Wang, K.; Guo, J.; Zhang, Y.Y.; Chen, J.; Guo, X.; et al. Characterization of microRNAs in serum: A novel class of biomarkers for diagnosis of cancer and other diseases. Cell Res. 2008, 18, 997-1006. [CrossRef] [PubMed]

17. Valadi, H.; Ekström, K.; Bossios, A.; Sjöstrand, M.; Lee, J.J.; Lötvall, J.O. Exosome-mediated transfer of mRNAs and microRNAs is a novel mechanism of genetic exchange between cells. Nat. Cell Biol. 2007, 9, 654-659. [CrossRef]

18. Gallo, A.; Tandon, M.; Alevizos, I.; Illei, G.G. The majority of microRNAs detectable in serum and saliva is concentrated in exosomes. PLoS ONE 2012, 7, e30679. [CrossRef]

19. Xiong, D.D.; Lv, J.; Wei, K.L.; Feng, Z.B.; Chen, J.T.; Liu, K.C.; Chen, G.; Luo, D.Z. A nine-miRNA signature as a potential diagnostic marker for breast carcinoma: An integrated study of 1,110 cases. Oncol. Rep. 2017. [CrossRef]

20. Tüfekci, K.U.; Öner, M.G.; Meuwissen, R.L.J.; Genç, Ş. The role of microRNAs in human diseases. Methods Mol. Biol. 2014. [CrossRef]

21. Paul, P.; Chakraborty, A.; Sarkar, D.; Langthasa, M.; Rahman, M.; Bari, M.; Singha, R.K.S.; Malakar, A.K.; Chakraborty, S. Interplay between miRNAs and human diseases. J. Cell. Physiol. 2018. [CrossRef]

22. Liang, Y.; Ridzon, D.; Wong, L.; Chen, C. Characterization of microRNA expression profiles in normal human tissues. Bmc Genom. 2007, 8, 166. [CrossRef]

23. Morales-Prieto, D.M.; Chaiwangyen, W.; Ospina-Prieto, S.; Schneider, U.; Herrmann, J.; Gruhn, B.; Markert, U.R. MicroRNA expression profiles of trophoblastic cells. Placenta 2012, 33, 725-734. [CrossRef] [PubMed]

24. Sun, D.G.; Tian, S.; Zhang, L.; Hu, Y.; Guan, C.Y.; Ma, X.; Xia, H.F. The miRNA-29b Is Downregulated in Placenta During Gestational Diabetes Mellitus and May Alter Placenta Development by Regulating Trophoblast Migration and Invasion Through a HIF3A-Dependent Mechanism. Front. Endocrinol. (Lausanne). 2020, 11, 1-16. [CrossRef] [PubMed]

25. Li, L.; Wang, S.; Li, H.; Wan, J.; Zhou, Q.; Zhou, Y.; Zhang, C. microRNA-96 protects pancreatic $\beta$-cell function by targeting PAK1 in gestational diabetes mellitus. BioFactors 2018, 44, 539-547. [CrossRef] [PubMed]

26. Cao, J.-L.L.; Zhang, L.; Li, J.; Tian, S.; Lv, X.-D.D.; Wang, X.-Q.Q.; Su, X.; Li, Y.; Hu, Y.; Ma, X.; et al. Up-regulation of miR-98 and unraveling regulatory mechanisms in gestational diabetes mellitus. Sci. Rep. 2016, 6, 1-14. [CrossRef]

27. Strutz, J.; Cvitic, S.; Hackl, H.; Kashofer, K.; Appel, H.M.; Thüringer, A.; Desoye, G.; Koolwijk, P.; Hiden, U. Gestational diabetes alters microRNA signatures in human feto-placental endothelial cells depending on fetal sex. Clin. Sci. 2018, 132, $2437-2449$. [CrossRef] 
28. Gillet, V.; Ouellet, A.; Stepanov, Y.; Rodosthenous, R.S.; Croft, E.K.; Brennan, K.; Abdelouahab, N.; Baccarelli, A.; Takser, L. miRNA Profiles in Extracellular Vesicles From Serum Early in Pregnancies Complicated by Gestational Diabetes Mellitus. J. Clin. Endocrinol. Metab. 2019, 104, 5154-5166. [CrossRef]

29. Ma, T.; Jiang, H.; Gao, Y.; Zhao, Y.; Dai, L.; Xiong, Q.; Xu, Y.; Zhao, Z.; Zhang, J. Microarray analysis of differentially expressed microRNAs in non-regressed and regressed bovine corpus luteum tissue; microRNA-378 may suppress luteal cell apoptosis by targeting the interferon gamma receptor 1 gene. J. Appl. Genet. 2011, 52, 481-486. [CrossRef]

30. Martino, F.; Magenta, A.; Pannarale, G.; Martino, E.; Zanoni, C.; Perla, F.M.; Puddu, P.E.; Barillà, F.; Mughal, W.; Nguyen, L.; et al. MEG3 damages fetal endothelial function induced by gestational diabetes mellitus via AKT pathway. Front. Endocrinol. (Lausanne). 2019, 9, 156-159. [CrossRef]

31. Hocaoglu, M.; Demirer, S.; Loclar Karaalp, I.; Kaynak, E.; Attar, E.; Turgut, A.; Karateke, A.; Komurcu-Bayrak, E. Identification of miR-16-5p and miR-155-5p microRNAs differentially expressed in circulating leukocytes of pregnant women with polycystic ovary syndrome and gestational diabetes. Gynecol. Endocrinol. 2020, 1-5. [CrossRef]

32. Hocaoglu, M.; Demirer, S.; Senturk, H.; Turgut, A.; Komurcu-Bayrak, E. Differential expression of candidate circulating microRNAs in maternal blood leukocytes of the patients with preeclampsia and gestational diabetes mellitus. Pregnancy Hypertens. 2019, 17, 5-11. [CrossRef]

33. Zhao, C.; Dong, J.; Jiang, T.; Shi, Z.; Yu, B.; Zhu, Y.; Chen, D.; Xu, J.; Huo, R.; Dai, J.; et al. Early second-trimester serum miRNA profiling predicts gestational diabetes mellitus. PLOS ONE 2011, 6, e23925. [CrossRef] [PubMed]

34. Martínez-Ibarra, A.; Martínez-Razo, L.D.; Vázquez-Martínez, E.R.; Martínez-Cruz, N.; Flores-Ramírez, R.; García-Gómez, E.; López-López, M.; Ortega-González, C.; Camacho-Arroyo, I.; Cerbón, M. Unhealthy levels of phthalates and bisphenol a in mexican pregnant women with gestational diabetes and its association to altered expression of miRNAs involved with metabolic disease. Int. J. Mol. Sci. 2019, 20, 3343. [CrossRef] [PubMed]

35. Yoffe, L.; Polsky, A.; Gilam, A.; Raff, C.; Mecacci, F.; Ognibene, A.; Crispi, F.; Gratacós, E.; Kanety, H.; Mazaki-Tovi, S.; et al. Early diagnosis of gestational diabetes mellitus using circulating microRNAs. Eur. J. Endocrinol. 2019, 181, 565-577. [CrossRef] [PubMed]

36. Carreras-Badosa, G.; Bonmatí, A.; Ortega, F.-J.; Mercader, J.-M.; Guindo-Martínez, M.; Torrents, D.; Prats-Puig, A.; MartinezCalcerrada, J.-M.; Platero-Gutierrez, E.; De Zegher, F.; et al. Altered Circulating miRNA Expression Profile in Pregestational and Gestational Obesity. J. Clin. Endocrinol. Metab. 2015, 100, E1446-E1456. [CrossRef]

37. Xue, Y.; Lv, J.; Xu, P.; Gu, L.; Cao, J.; Xu, L.; Xue, K.; Li, Q. Identification of microRNAs and genes associated with hyperandrogenism in the follicular fluid of women with polycystic ovary syndrome. J. Cell. Biochem. 2017, 3913-3921. [CrossRef]

38. Wander, P.L.; Boyko, E.J.; Hevner, K.; Parikh, V.J.; Tadesse, M.G.; Sorensen, T.K.; Williams, M.A.; Enquobahrie, D.A. Circulating early- and mid-pregnancy microRNAs and risk of gestational diabetes. Diabetes Res. Clin. Pr. 2017, 132, 1-9. [CrossRef]

39. Sebastiani, G.; Guarino, E.; Grieco, G.E.; Formichi, C.; Poggi, C.D.; Ceccarelli, E.; Dotta, F. Circulating microRNA (miRNA) expression profiling in plasma of patients with gestational diabetes mellitus reveals upregulation of miRNA miR-330-3p. Front. Endocrinol. (Lausanne). 2017, 8, 1-12. [CrossRef]

40. Lamadrid-Romero, M.; Solís, K.H.; Cruz-Reséndiz, M.S.; Pérez, J.E.; Díaz, N.F.; Flores-Herrera, H.; García-López, G.; Perichart, O.; Reyes-Muñoz, E.; Arenas-Huertero, F.; et al. Central nervous system development-related microRNAs levels increase in the serum of gestational diabetic women during the first trimester of pregnancy. Neurosci. Res. 2018, 130, 8-22. [CrossRef]

41. Nair, S.; Jayabalan, N.; Guanzon, D.; Palma, C.; Scholz-Romero, K.; Elfeky, O.; Zuñiga, F.; Ormazabal, V.; Diaz, E.; Rice, G.E.; et al. Human placental exosomes in gestational diabetes mellitus carry a specific set of miRNAs associated with skeletal muscle insulin sensitivity. Clin. Sci. 2018, 132, 2451-2467. [CrossRef]

42. Pheiffer, C.; Dias, S.; Rheeder, P.; Adam, S. Decreased Expression of Circulating miR-20a-5p in South African Women with Gestational Diabetes Mellitus. Mol. Diagn. 2018, 22, 345-352. [CrossRef]

43. Tagoma, A.; Alnek, K.; Kirss, A.; Uibo, R.; Haller-Kikkatalo, K. MicroRNA profiling of second trimester maternal plasma shows upregulation of miR-195-5p in patients with gestational diabetes. Gene 2018, 672, 137-142. [CrossRef]

44. Jelsma, J.G.M.; van Poppel, M.N.M.; Galjaard, S.; Desoye, G.; Corcoy, R.; Devlieger, R.; van Assche, A.; Timmerman, D.; Jans, G.; Harreiter, J.; et al. DALI: Vitamin D and lifestyle intervention for gestational diabetes mellitus (GDM) prevention: An European multicentre, randomised trial—study protocol. Bmc Pregnancy Childbirth 2013, 13, 1. [CrossRef] [PubMed]

45. Simmons, D.; Devlieger, R.; van Assche, A.; Jans, G.; Galjaard, S.; Corcoy, R.; Adelantado, J.M.; Dunne, F.; Desoye, G.; Harreiter, J.; et al. Effect of Physical Activity and/or Healthy Eating on GDM Risk: The DALI Lifestyle Study. J. Clin. Endocrinol. Metab. 2017, 102, 903-913. [CrossRef] [PubMed]

46. Corcoy, R.; Mendoza, L.C.; Simmons, D.; Desoye, G.; Adelantado, J.M.; Chico, A.; Devlieger, R.; van Assche, A.; Galjaard, S.; Timmerman, D.; et al. The DALI vitamin D randomized controlled trial for gestational diabetes mellitus prevention: No major benefit shown besides vitamin D sufficiency. Clin. Nutr. 2020, 39. [CrossRef] [PubMed]

47. Matthews, D.R.; Hosker, J.P.; Rudenski, A.S.; Naylor, B.A.; Treacher, D.F.; Turner, R.C. Homeostasis model assessment: Insulin resistance and $\beta$-cell function from fasting plasma glucose and insulin concentrations in man. Diabetologia 1985. [CrossRef] [PubMed]

48. Katz, A.; Nambi, S.S.; Mather, K.; Baron, A.D.; Follmann, D.A.; Sullivan, G.; Quon, M.J. Quantitative insulin sensitivity check index: A simple, accurate method for assessing insulin sensitivity in humans. J. Clin. Endocrinol. Metab. 2000. [CrossRef] 
49. Mari, A.; Pacini, G.; Murphy, E.; Ludvik, B.; Nolan, J.J. A model-based method for assessing insulin sensitivity from the oral glucose tolerance test. Diabetes Care 2001. [CrossRef]

50. Matsuda, M.; DeFronzo, R.A. Insulin sensitivity indices obtained from oral glucose tolerance testing: Comparison with the euglycemic insulin clamp. Diabetes Care 1999. [CrossRef]

51. Patarrão, R.S.; Wayne Lautt, W.; Paula Macedo, M. Assessment of methods and indexes of insulin sensitivity. Rev. Port. Endocrinol. Diabetes E Metab. 2014. [CrossRef]

52. Agarwal, V.; Bell, G.W.; Nam, J.W.; Bartel, D.P. Predicting effective microRNA target sites in mammalian mRNAs. Elife 2015, 4, 1-38. [CrossRef]

53. Mi, H.; Muruganujan, A.; Huang, X.; Ebert, D.; Mills, C.; Guo, X.; Thomas, P.D. Protocol Update for large-scale genome and gene function analysis with the PANTHER classification system (v.14.0). Nat. Protoc. 2019. [CrossRef] [PubMed]

54. Wickham, H. ggplot2: Elegant Graphics for Data Analysis; Springer: New York, NY, USA, 2016; ISBN 978-3-319-24275-0.

55. Zhu, Y.; Tian, F.; Li, H.; Zhou, Y.; Lu, J.; Ge, Q. Profiling maternal plasma microRNA expression in early pregnancy to predict gestational diabetes mellitus. Int. J. Gynecol. Obs. 2015, 130, 49-53. [CrossRef] [PubMed]

56. Ge, Q.; Zhu, Y.; Li, H.; Tian, F.; Xie, X.; Bai, Y. Differential expression of circulating miRNAs in maternal plasma in pregnancies with fetal macrosomia. Int. J. Mol. Med. 2015, 35, 81-91. [CrossRef] [PubMed]

57. Cao, Y.L.; Jia, Y.J.; Xing, B.H.; Shi, D.D.; Dong, X.J. Plasma microRNA-16-5p, -17-5p and -20a-5p: Novel diagnostic biomarkers for gestational diabetes mellitus. J. Obs. Gynaecol. Res. 2017, 43, 974-981. [CrossRef]

58. Pritchard, C.C.; Kroh, E.; Wood, B.; Arroyo, D.J.; Dougherty, J.K.; Miyaji, M.M.; Tait, F.J.; Tewari, M. Blood Cell Origin of Circulating MicroRNAs: A Cautionary Note for Cancer Biomarkers Studies. Cancer Prev. Res. 2012, 5, 492-497. [CrossRef]

59. Liang, Y.Z.; Dong, J.; Zhang, J.; Wang, S.; He, Y.; Yan, Y.X. Identification of neuroendocrine stress response-related circulating MicroRNAs as biomarkers for type 2 diabetes mellitus and insulin resistance. Front. Endocrinol. (Lausanne). 2018. [CrossRef]

60. Khaliq, O.P.; Murugesan, S.; Moodley, J.; Mackraj, I. Differential expression of miRNAs are associated with the insulin signaling pathway in preeclampsia and gestational hypertension. Clin. Exp. Hypertens. 2018. [CrossRef]

61. Salomon, C.; Scholz-Romero, K.; Sarker, S.; Sweeney, E.; Kobayashi, M.; Correa, P.; Longo, S.; Duncombe, G.; Mitchell, M.D.; Rice, G.E.; et al. Gestational Diabetes Mellitus Is Associated With Changes in the Concentration and Bioactivity of Placenta-Derived Exosomes in Maternal Circulation Across Gestation. Diabetes 2016, 65, 598-609. [CrossRef]

62. Mattis, A.N.; Song, G.; Hitchner, K.; Kim, R.Y.; Lee, A.Y.; Sharma, A.D.; Malato, Y.; Mcmanus, M.T.; Esau, C.C.; Koller, E.; et al. A screen in mice uncovers repression of lipoprotein lipase by microRNA-29a as a mechanism for lipid distribution away from the liver. Hepatology 2015. [CrossRef]

63. Dooley, J.; Garcia-Perez, J.E.; Sreenivasan, J.; Schlenner, S.M.; Vangoitsenhoven, R.; Papadopoulou, A.S.; Tian, L.; Schonefeldt, S.; Serneels, L.; Deroose, C.; et al. The microRNA-29 family dictates the balance between homeostatic and pathological glucose handling in diabetes and obesity. Diabetes 2016. [CrossRef]

64. Bagge, A.; Clausen, T.R.; Larsen, S.; Ladefoged, M.; Rosenstierne, M.W.; Larsen, L.; Vang, O.; Nielsen, J.H.; Dalgaard, L.T. MicroRNA-29a is up-regulated in beta-cells by glucose and decreases glucose-stimulated insulin secretion. Biochem. Biophys. Res. Commun. 2012, 426, 266-272. [CrossRef] [PubMed]

65. Herrera, B.M.; Lockstone, H.E.; Taylor, J.M.; Ria, M.; Barrett, A.; Collins, S.; Kaisaki, P.; Argoud, K.; Fernandez, C.; Travers, M.E.; et al. Global microRNA expression profiles in insulin target tissues in a spontaneous rat model of type 2 diabetes. Diabetologia 2010, 53, 1099-1109. [CrossRef] [PubMed]

66. Udesen, P.B.; Glintborg, D.; Sørensen, A.E.; Svendsen, R.; Nielsen, N.L.S.; Wissing, M.L.M.; Andersen, M.S.; Englund, A.L.M.; Dalgaard, L.T. Metformin decreases miR-122, miR-223 and miR-29a in women with polycystic ovary syndrome. Endocr. Connect. 2020. [CrossRef] [PubMed]

67. Rees, W.D.; Wilson, F.A.; Maloney, C.A. Sulfur amino acid metabolism in pregnancy: The impact of methionine in the maternal diet. J. Nutr. 2006, 136, 1701S-1705S.

68. Lassance, L.; Miedl, H.; Absenger, M.; Diaz-Perez, F.; Lang, U.; Desoye, G.; Hiden, U. Hyperinsulinemia Stimulates Angiogenesis of Human Fetoplacental Endothelial Cells: A Possible Role of Insulin in Placental Hypervascularization in Diabetes Mellitus. J. Clin. Endocrinol. Metab. 2013, 98, E1438-E1447. [CrossRef]

69. Hiden, U.; Lassance, L.; Tabrizi, N.G.; Miedl, H.; Tam-Amersdorfer, C.; Cetin, I.; Lang, U.; Desoye, G. Fetal Insulin and IGF-II Contribute to Gestational Diabetes Mellitus (GDM)-Associated Up-Regulation of Membrane-Type Matrix Metalloproteinase 1 (MT1-MMP) in the Human Feto-Placental Endothelium. J. Clin. Endocrinol. Metab. 2012, 97, 3613-3621. [CrossRef]

70. Ji, Y.; Wu, Z.; Dai, Z.; Sun, K.; Wang, J.; Wu, G. Nutritional epigenetics with a focus on amino acids: Implications for the development and treatment of metabolic syndrome. J. Nutr. Biochem. 2016. [CrossRef]

71. Freyberg, Z.; Saavedra, J.M. Trace Amines and Trace Amine-Associated Receptors: A New Frontier in Cell Signaling. Cell. Mol. Neurobiol. 2020. [CrossRef]

72. Williams, Z.; Ben-Dov, I.Z.; Elias, R.; Mihailovic, A.; Brown, M.; Rosenwaks, Z.; Tuschl, T. Comprehensive profiling of circulating microRNA via small RNA sequencing of cDNA libraries reveals biomarker potential and limitations. Proc. Natl. Acad. Sci. 2013, 110, 4255-4260. [CrossRef]

73. Schratt, G.M.; Tuebing, F.; Nigh, E.A.; Kane, C.G.; Sabatini, M.E.; Kiebler, M.; Greenberg, M.E. A brain-specific microRNA regulates dendritic spine development. Nature 2006, 439, 283-289. [CrossRef] 
74. Wang, H.W.; Su, S.H.; Wang, Y.L.; Chang, S.T.; Liao, K.H.; Lo, H.H.; Chiu, Y.L.; Hsieh, T.H.; Huang, T.S.; Lin, C.S.; et al. MicroRNA134 contributes to glucose-induced endothelial cell dysfunction and this effect can be reversed by far-infrared irradiation. PLoS ONE 2016, 11. [CrossRef]

75. Jaskolka, D.; Retnakaran, R.; Zinman, B.; Kramer, C.K. Sex of the baby and risk of gestational diabetes mellitus in the mother: A systematic review and meta-analysis. Diabetologia 2015. [CrossRef] [PubMed]

76. Luo, S.; Cao, N.; Tang, Y.; Gu, W. Identification of key microRNAs and genes in preeclampsia by bioinformatics analysis. PLoS ONE 2017. [CrossRef] [PubMed]

77. Zou, A.X.; Chen, B.; Li, Q.X.; Liang, Y.C. MiR-134 inhibits infiltration of trophoblast cells in placenta of patients with preeclampsia by decreasing ITGB1 expression. Eur. Rev. Med. Pharm. Sci. 2018. [CrossRef]

78. Kirwan, J.P.; Hauguel-De Mouzon, S.; Lepercq, J.; Challier, J.-C.; Huston-Presley, L.; Friedman, J.E.; Kalhan, S.C.; Catalano, P.M. TNF- Is a Predictor of Insulin Resistance in Human Pregnancy. Diabetes 2002, 51, 2207-2213. [CrossRef] [PubMed]

79. Lan, G.; Xie, W.; Li, L.; Zhang, M.; Liu, D.; Tan, Y.L.; Cheng, H.P.; Gong, D.; Huang, C.; Zheng, X.L.; et al. MicroRNA-134 actives lipoprotein lipase-mediated lipid accumulation and inflammatory response by targeting angiopoietin-like 4 in THP-1 macrophages. Biochem. Biophys. Res. Commun. 2016. [CrossRef] [PubMed]

80. Ameling, S.; Kacprowski, T.; Chilukoti, R.K.; Malsch, C.; Liebscher, V.; Suhre, K.; Pietzner, M.; Friedrich, N.; Homuth, G.; Hammer, E.; et al. Associations of circulating plasma microRNAs with age, body mass index and sex in a population-based study. Bmc Med. Genom. 2015. [CrossRef]

81. Wang, R.; Hong, J.; Cao, Y.; Shi, J.; Gu, W.; Ning, G.; Zhang, Y.; Wang, W. Elevated circulating microRNA-122 is associated with obesity and insulin resistance in young adults. Eur. J. Endocrinol. 2015. [CrossRef]

82. Willeit, P.; Skroblin, P.; Moschen, A.R.; Yin, X.; Kaudewitz, D.; Zampetaki, A.; Barwari, T.; Whitehead, M.; Ramírez, C.M.; Goedeke, L.; et al. Circulating MicroRNA-122 Is Associated With the Risk of New-Onset Metabolic Syndrome and Type 2 Diabetes. Diabetes 2017, 66, 347-357. [CrossRef]

83. Hess, A.L.; Larsen, L.H.; Udesen, P.B.; Sanz, Y.; Larsen, T.M.; Dalgaard, L.T. Levels of Circulating miR-122 are Associated with Weight Loss and Metabolic Syndrome. Obesity 2020. [CrossRef]

84. Fornes, D.; Heinecke, F.; Roberti, S.L.; White, V.; Capobianco, E.; Jawerbaum, A. Proinflammation in maternal and fetal livers and circulating miR-122 dysregulation in a GDM rat model induced by intrauterine programming. Mol. Cell. Endocrinol. 2020, 510, 110824. [CrossRef]

85. Harreiter, J.; Desoye, G.; van Poppel, M.N.M.; Kautzky-Willer, A.; Dunne, F.; Corcoy, R.; Devlieger, R.; Simmons, D.; Adelantado, J.M.; Damm, P.; et al. The Effects of Lifestyle and/or Vitamin D Supplementation Interventions on Pregnancy Outcomes: What Have We Learned from the DALI Studies? Curr. Diab. Rep. 2019, 19. [CrossRef] [PubMed]

86. Harreiter, J.; Simmons, D.; Desoye, G.; Corcoy, R.; Adelantado, J.M.; Devlieger, R.; van Assche, A.; Galjaard, S.; Damm, P.; Mathiesen, E.R.; et al. IADPSG and WHO 2013 Gestational Diabetes Mellitus Criteria Identify Obese Women With Marked Insulin Resistance in Early Pregnancy. Diabetes Care 2016, 39, e90-e92. [CrossRef] [PubMed]

87. Huvinen, E.; Eriksson, J.G.; Stach-Lempinen, B.; Tiitinen, A.; Koivusalo, S.B. Heterogeneity of gestational diabetes (GDM) and challenges in developing a GDM risk score. Acta Diabetol. 2018, 55, 1251-1259. [CrossRef] [PubMed]

88. Powe, C.E.; Hivert, M.-F.; Udler, M.S. Defining Heterogeneity Among Women With Gestational Diabetes Mellitus. Diabetes 2020, 69, 2064-2074. [CrossRef] [PubMed]

89. Ma, D.; Luque-Fernandez, M.A.; Bogdanet, D.; Desoye, G.; Dunne, F.; Halperin, J.A. Plasma Glycated CD59 Predicts Early Gestational Diabetes and Large for Gestational Age Newborns. J. Clin. Endocrinol. Metab. 2020, 105, e1033-e1040. [CrossRef]

90. Immanuel, J.; Simmons, D.; Desoye, G.; Corcoy, R.; Adelantado, J.M.; Devlieger, R.; Lapolla, A.; Dalfra, M.G.; Bertolotto, A.; Harreiter, J.; et al. Performance of early pregnancy HbA1c for predicting gestational diabetes mellitus and adverse pregnancy outcomes in obese European women. Diabetes Res. Clin. Pr. 2020, 168, 108378. [CrossRef] [PubMed]

91. Mendoza, L.C.; Harreiter, J.; Simmons, D.; Desoye, G.; Adelantado, J.M.; Juarez, F.; Chico, A.; Devlieger, R.; Van Assche, A.; Galjaard, S.; et al. Risk factors for hyperglycemia in pregnancy in the DALI study differ by period of pregnancy and OGTT time point. Eur. J. Endocrinol. 2018, 179, 39-49. [CrossRef]

92. van Hoorn, F.; Koster, M.P.H.; Naaktgeboren, C.A.; Groenendaal, F.; Kwee, A.; Lamain-de Ruiter, M.; Franx, A.; Bekker, M.N. Prognostic models versus single risk factor approach in first-trimester selective screening for gestational diabetes mellitus: A prospective population-based multicentre cohort study. Bjog An. Int. J. Obs. Gynaecol. 2020, 1-10. [CrossRef] 